\title{
Linfoma de Hodgkin em Pacientes HIV Positivo em Uso de Antirretrovirais de Alta Efetividade
}

doi: https://doi.org/10.32635/2176-9745.RBC.2021v67n2.825

\author{
Hodgkin Lymphoma in HIV Positive Patients in The Use of High-Effective Antiretroviral \\ Linfoma de Hodgkin en Pacientes VIH Positivos en el Uso de Antiretrovirales de Alta Efectividad
}

Sávio da Silva Araújo'; Carlos Genilson Freire Monteiro²; Tiago Lima Sampaio3; Aline de Albuquerque Oliveira4

RESUMO

Introduçáo: A capacidade do vírus da imunodeficiência humana (HIV) de invadir células do sistema imunológico, principalmente células T CD4+, para se multiplicar e manter-se vivo, quando não revertido, possui, como desfecho inevitável, a síndrome da imunodeficiência adquirida (SIDA), evento no qual os pacientes começam a apresentar doenças secundárias como infecçóes oportunistas e câncer. Objetivo: Identificar casos de linfoma de Hodgkin em pacientes HIV+ em uso dos antirretrovirais de alta efetividade. Método: Estudo do tipo observacional transversal com delineamento exploratório e descritivo e abordagem quali-quantitativa, realizado durante o mês de outubro de 2018, a partir da análise de 57 prontuários de pacientes HIV+ diagnosticados com câncer e internados em um hospital localizado em Fortaleza, CE. Resultados: Foi identificado um total de 21 cânceres não definidores de SIDA. Destes, os mais comuns foram o câncer de pele com 14,3\% (3); seguido do câncer de mama com 9,5\% (2); linfoma de Hodgkin com 9,5\% (2); e o câncer de estômago com 9,5\% (2) dos casos. Conclusáo: Os dados obtidos no presente estudo colocam o linfoma de Hodgkin em segundo lugar entre os cânceres não definidores de SIDA encontrados. Contudo, ao considerar o baixo número de casos, resultante das limitações da pesquisa, essas informaçốes não permitem concluir sobre a real quantidade de linfomas de Hodgkin entre os demais cânceres não definidores de SIDA ocorridos em pacientes HIV+ na localidade, tampouco estimar a participação do HIV, carga viral, condição imunológica e coinfecções como fatores de risco.

Palavras-chave: Doença de Hodgkin; HIV; Síndrome de Imunodeficiência Adquirida; Antirretrovirais/uso terapêutico; Neoplasias.

\section{ABSTRACT}

Introduction: The ability of the human immunodeficiency virus (HIV) of invading immune system cells, especially CD4+ to multiply and stay alive, when not reversed, has as inevitable outcome the acquired immunodeficiency syndrome (AIDS), an event in which patients start to develop secondary diseases such as opportunistic infections and cancer. Objective: To identify cases of Hodgkin's lymphoma in HIV+ patients using highly effective antiretrovirals. Method: Cross-sectional observational study with exploratory and descriptive design and qualitative and quantitative approach, carried out during the month of October 2018 based on the analysis of 57 HIV-infected patients' charts diagnosed with cancer and admitted to a hospital located in Fortaleza, CE. Results: A total of 21 non-AIDS-defining cancers were detected. Of these, skin cancer, with $14.3 \%$ (3) followed by breast cancer, with $9.5 \%$ (2), Hodgkin's lymphoma, $9.5 \%$ (2) and stomach cancer, with $9.5 \%$ (2) were the most common cases. Conclusion: The data obtained in the present study rank Hodgkin's lymphoma in second place among the non-AIDS-defining cancers encountered. However, while considering the small number of cases, due to the study limitations, these data are scanty to conclude the actual quantity of Hodgkin's lymphoma among the non-AIDS-defining cancers occurred in HIV-positive patients locally or to estimate the participation of HIV, viral load, immune condition and co-infection as risk factors.

Key words: Hodgkin Disease; HIV; Acquired Immunodeficiency Syndrome; Anti-Retroviral Agents/therapeutic use; Neoplasms.

\section{RESUMEN}

Introducción: La capacidad del virus de inmunodeficiencia humana (VIH) para invadir las células del sistema inmunitario, especialmente las células T CD4 + para multiplicarse y mantenerse con vida, cuando no se revierte, tiene el resultado inevitable del síndrome de inmunodeficiencia adquirida (SIDA), evento en el que los pacientes comienzan a presentar enfermedades secundarias como infecciones oportunistas y cáncer. Objetivo: Identificar los casos de linfoma de Hodgkin en pacientes VIH+ utilizando los antirretrovirales de alta eficacia. Método: Este es un estudio observacional transversal con diseńo exploratorio y descriptivo y enfoque cualitativo, realizado durante octubre de 2018 a partir del análisis de 57 registros médicos de pacientes VIH + diagnosticados con cáncer y hospitalizados en un hospital ubicado en Fortaleza, CE. Resultados: Se identificaron un total de 21 cánceres que no definen el SIDA. De estos, los más comunes fueron cáncer de piel con 14,3\% (3), seguido de cáncer de seno con 9,5\% (2), linfoma de Hodgkin 9,5\% (2) y cáncer de estómago con 9,5\% (2) de los casos. Conclusión: Los datos obtenidos en el presente estudio colocan al linfoma de Hodgkin en segundo lugar entre los cánceres no definitorios de SIDA encontrados. Sin embargo, considerando el bajo número de casos resultantes de las limitaciones de la investigación, esta información no nos permite concluir acerca de la cantidad real de linfoma de Hodgkin entre los otros cánceres no definitorios de SIDA en pacientes VIH + en la localidad, ni estimar la participación del VIH, la carga viral, la condición inmune y las coinfecciones como factores de riesgo.

Palabras clave: Enfermedad de Hodgkin; VIH; Síndrome de Inmunodeficiencia Adquirida; Antirretrovirales/uso terapéutico; Neoplasias.

${ }^{1,2}$ Centro Universitário Fametro (Unifametro). Fortaleza (CE), Brasil. E-mails: saviosaviosi@gmail.com; genilson.monteiro09@gmail.com. Orcid iD: https://orcid. org/0000-0001-5491-5319; Orcid iD: https://orcid.org/0000-0002-4217-4039

3Universidade Federal do Ceará (UFC). Fortaleza (CE), Brasil. E-mail: tiagosampaio91@gmail.com. Orcid iD: https://orcid.org/0000-0002-3962-6508

${ }^{4}$ Centro Universitário Christus (Unichristus). Fortaleza (CE), Brasil. E-mail: alinealbuquer@hotmail.com. Orcid iD: https://orcid.org/0000-0002-5998-2606

Endereço para correspondência: Sávio da Silva Araújo. Rua Conselheiro Estelita, 500 - Centro. Fortaleza (CE), Brasil. CEP 60010-260. E-mail: saviosaviosi@gmail.com 


\section{INTRODUÇÃO}

A infecção pelo vírus da imunodeficiência humana (HIV), quando não tratada, resulta em imunossupressão. Isso, em razão da capacidade que o vírus possui de invadir células do sistema imunológico, principalmente células T CD4+, para então se multiplicar e manter-se vivo. Tal mecanismo, quando náo revertido, possui, como desfecho inevitável, a síndrome da imunodeficiência adquirida (SIDA), evento pelo qual os pacientes começam a apresentar doenças secundárias, como infecçóes oportunistas e câncer ${ }^{1}$.

Após a introdução da terapia antirretroviral de alta efetividade (TAAE) e o consequente aumento na expectativa de vida dos pacientes $\mathrm{HIV}+$ em virtude da diminuição da SIDA, um novo cenário, envolvendo patologias manifestadas na referida população, foi observado, principalmente em relação às neoplasias não definidoras de SIDA, como o linfoma de Hodgkin e os cânceres de fígado, anal, de próstata e de pulmão, que passaram a ter uma incidência aumentada quando comparadas a neoplasias definidoras de SIDA, como o sarcoma de Kaposi, câncer cervical invasivo e os linfomas não Hodgkin².

No Brasil, durante o período de 2007 a 2017, foram notificados, no Sistema de Agravos de Notificação (Sinan), 194.217 casos de infecção pelo HIV, estando o Sudeste (49,65\%), Sul (20,73\%) e Nordeste (15,59\%) entre as Regiốes com os maiores números de infectados ${ }^{3}$.

Em relação à SIDA, as notificações contabilizadas do ano 1980 a junho de 2017 resultaram no total de 882.810 casos, sendo 40 mil a média de registros nos últimos cinco anos. Quanto ao número de óbitos informados desde o início da epidemia (1980) até o ano 2016 no Brasil, foram 316.088, havendo, a partir de 2014, após a política de tratamento para todos, uma queda de 11,9\% no coeficiente de mortalidade por SIDA padronizado para o país ${ }^{3}$.

Sobre algumas neoplasias não definidoras de SIDA durante o período de 2000 a 2015 no Brasil, a incidência e o número de mortos obtidos a partir do Registro de Câncer de Base Populacional (RCBP) foi, respectivamente, de 7.043 e 7.499 para linfoma de Hodgkin; 12.611 e 113.973 para câncer de fígado; 3.897 e 4.086 para câncer anal; 57.677 e 320.912 para câncer de pulmão; e 116.321 e 181.251 para o câncer de próstata ${ }^{4,5}$.

Entre os fatores de risco comumente citados para a maioria dos cânceres que não definem SIDA, estão o avanço da idade, tabagismo e histórico familiar ${ }^{6-8}$, com exceção para o linfoma de Hodgkin, que possui como principais contribuintes no seu desenvolvimento, além dos fatores de risco já mencionados, infecçôes pelo HIV; vírus linfotrópico da célula humana-1 (HTLV-1) e o vírus Epstein-Barr (EBV) ${ }^{9-11}$.

A linfocitopenia, resultante da ação do vírus HIV, funciona como um estímulo para a medula óssea, que, na tentativa de reverter o quadro de imunossupressão, estimula a linfopoiese dependente da interação de células CD34 com células CD4+ infectadas, de modo a resultar na exaustão e na falha na produção das novas células $\mathrm{B}$. A perturbação da hematopoese, associada ao volume aumentado de células precursoras na medula óssea, eleva as chances de erros genéticos e incidência de linfomas em pacientes $\mathrm{HIV}+{ }^{12}$.

Outro fator relacionado à alta produção das células B ocorre pela presença da proteína p-17 presente no envelope do HIV. Esta, por sua vez, é também capaz de estimular a formação de novos vasos sanguíneos, podendo assim promover, além da linfomagênese, a disseminação do linfoma ${ }^{12}$.

Taylor et al. ${ }^{13}$ inferem ainda que, conforme a cronicidade do paciente infectado pelo HIV advinda da eficácia dos antirretrovirais, o linfoma de Hodgkin poderá tornar-se uma complicação cada vez mais importante nesses indivíduos.

Embora, atualmente alguns países já venham discutido sobre a infecção pelo HIV e sobre os cânceres não definidores de SIDA, no Brasil, informaçóes advindas do cruzamento desses dados ainda são insuficientes, principalmente quando se deseja obter características dos pacientes HIV+ acometidos com tipos específicos de câncer.

A partir dessa necessidade, e com base nos fatores de riscos também mencionados, objetiva-se, neste trabalho, identificar, entre as neoplasias não definidoras de SIDA diagnosticadas nos pacientes HIV + acompanhados em um hospital de referência de Fortaleza, CE, durante o uso dos antirretrovirais de alta efetividade, casos de linfoma de Hodgkin, caracterizando esses pacientes conforme idade, sexo, contagem de células CD4+, carga viral, histórico de coinfecçóes e esquema antirretroviral utilizado até a diagnose de câncer.

\section{MÉTODO}

Estudo do tipo transversal retrospectivo, que buscou analisar o fator (pacientes HIV+ em uso de antirretrovirais) e o efeito (linfoma de Hodgkin) em um mesmo momento histórico, e observacional, por não haver nenhuma intervenção por parte dos pesquisadores. Além disso, trata-se de um trabalho exploratório, pois buscou-se nesta pesquisa a coleta de dados ainda náo fornecidos na localidade; e descritivo, tendo em vista que serão detalhados nos resultados os casos dos pacientes que se encaixaram nos critérios de inclusão da pesquisa. 
A abordagem foi quali-quantitativa. Na qualitativa, foram descritas as características, como sexo, faixa etária, tipo de tratamento antirretroviral desses pacientes e quando ocorridos também casos de coinfecções. Já na quantitativa, foram estimados todos os casos de neoplasias não definidoras de SIDA registrados em prontuários de pacientes HIV+ em uso de terapia antirretroviral para que fosse possível a obtenção do número dos casos de linfoma de Hodgkin na referida população.

O estudo foi realizado no Hospital São José de Doenças Infecciosas (HSJ) de Fortaleza, CE, a partir de prontuários de pacientes HIV+ internados de janeiro de 2013 a setembro de 2018. Todos os dados dos prontuários foram coletados e analisados no Serviço de Arquivo Médico e Estatística (SAME) do HSJ, durante o mês de outubro de 2018.

Foram utilizados, como fonte inicial para obtenção dos números dos prontuários a serem analisados, livros de altas e óbitos, disponíveis no SAME do HSJ. A partir deles, tornou-se possível o acesso a todos os prontuários de pacientes HIV+ hospitalizados que tiveram diagnóstico de câncer definidores e não definidores de SIDA durante o período de janeiro de 2013 a setembro de 2018.

Os critérios de inclusão foram prontuários de pacientes $\mathrm{HIV}+$ em uso de terapia antirretroviral diagnosticados com neoplasia não definidora de SIDA que tivessem informações sobre carga viral e contagem de células $\mathrm{T}$ CD4+, sendo este último não necessário em casos de pacientes com carga viral indetectável, em razão dos protocolos clínicos que orientam a não solicitação de contagem de células T CD4+ após a primeira obtenção de carga viral indetectável. A justificativa para os critérios determinados se deu pelo fato de que o entendimento sobre a condição imunológica, assim como a infecção pelo vírus HIV por meio da quantidade de cópias do vírus no sangue, e o uso dos antirretrovirais podem pressupor se os casos de neoplasias encontrados, principalmente o linfoma de Hodgkin, estão relacionados com a condição sorológica da população em estudo.

Portanto, foram selecionados, por fazerem parte dos critérios de inclusão, 21 prontuários de pacientes HIV+ com histórico de uso de antirretrovirais de alta efetividade e que tiveram diagnóstico de alguma neoplasia não definidora de SIDA. Logo após, foi iniciada investigação sobre as seguintes variáveis: idade; sexo (identificar se faixa etária média e sexo condiz com o perfil relatado por outros países); tipo de câncer não definidor de SIDA (identificar se existe predominância para o linfoma de Hodgkin); primeira contagem da carga viral e primeira contagem de células T CD4+ após diagnóstico de HIV+; última contagem da carga viral e última contagem de células $\mathrm{T}$ CD4+ antes do diagnóstico de câncer (entender a evolução imunológica e sorológica do paciente após diagnóstico de HIV até o diagnóstico de câncer não definidor de SIDA); histórico de coinfecções (pressupor relação do agente infeccioso com câncer ou potencialização da predisposição de câncer); esquema antirretroviral utilizado até o diagnóstico de câncer (discutir se o uso durante tratamento do linfoma de Hodgkin possui algum impacto na eficácia do tratamento e/ou segurança do paciente) e histórico de adesão ao tratamento antirretroviral, sendo este último avaliado a partir dos registros médicos nos prontuários e associado aos resultados da contagem de células TCD4+ e carga viral após início do tratamento.

Foram selecionados também, para posterior análise, dez prontuários de pacientes HIV+ com câncer, mas que não havia especificação quanto ao subtipo, por exemplo, linfoma e neoplasia maligna, permanecendo no estudo apenas os casos confirmados, após investigação, de cânceres não definidores de SIDA.

Quanto aos critérios de exclusão, foram descartados de análises prontuários de pacientes HIV+ que tiveram diagnóstico de neoplasia definidora de SIDA ou que não preencheram os critérios de inclusão.

Foram excluídos, por não fazerem parte dos critérios de inclusão deste estudo, além dos prontuários de pacientes diagnosticados com neoplasias definidoras de SIDA (sarcoma de Kaposi, linfomas náo Hodgkin, câncer cervical invasivo), os prontuários dos pacientes diagnosticados com câncer cujo subtipo não foi especificado ou que, em nenhum momento, fizeram uso de antirretrovirais de alta efetividade.

Para ajudar na obtenção e organização das informaçôes a partir da análise total de cada prontuário, foi elaborado um formulário de acompanhamento das variáveis. Os dados coletados foram transferidos para uma planilha do software Microsoft Excel (2013), atualizados conforme seguimento do estudo e analisados. Além dos dados estatísticos descritivos, alguns foram também convertidos em figuras e tabela para assim serem apresentados nos resultados obtidos.

A presente pesquisa foi aprovada pelo Comitê de Ética em Pesquisa do Centro Universitário Fametro (Unifametro) sob o número CAAE de 99291718.6.0000.5618 e parecer 2.925.389.

\section{RESULTADOS}

A presente pesquisa, realizada com fontes secundárias de dados referentes a todos os pacientes HIV+ internados em um período de seis anos, resultou em um total de 57 prontuários a serem investigados. Destes, 26 pertenciam a pacientes diagnosticados com câncer definidor de SIDA, outros dez prontuários eram de pacientes que não 
tiveram seu tipo de câncer especificado, totalizando assim 36 prontuários não selecionados para o presente estudo.

Quanto aos prontuários selecionados, foram encontrados 21 cânceres não definidores de SIDA (Figura 1). Destes, identificaram-se casos de câncer de pele com 14,3\% (3); seguido do câncer de mama com 9,5\% (2); linfoma de Hodgkin com 9,5\% (2); câncer de estômago com 9,5\% (2); e 4,8\% (1) para os casos de câncer de pleura, pulmão, orofaringe, cólon, reto, pênis, próstata, boca, esôfago, carcinoma anaplásico, mieloma múltiplo e leucemia.

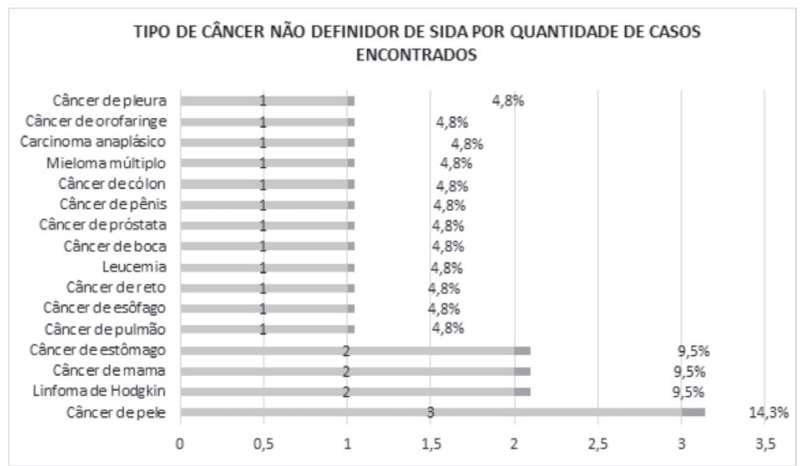

Figura 1. Número de casos por tipo de câncer não definidor de SIDA em pacientes HIV + internados em hospital de referência em Fortaleza, Ceará, janeiro de 2013 a setembro de 2018

Em relação aos pacientes, $81 \%$ (17) eram do sexo masculino e $19 \%$ (4) do sexo feminino. Para o sexo masculino, a idade variou de 37 a 70 anos, com média igual a 52 anos. No sexo feminino, a variação foi de 37 a 65 anos com média de 50 anos. Quanto aos pacientes com linfoma de Hodgkin, 100\% (2) eram do sexo masculino, com idade mínima igual a 40 anos, idade máxima igual a 49 anos e média igual a 45 anos.

Dos 21 prontuários analisados, apenas 13 forneciam informaçóes sobre as variáveis: "primeira contagem de células CD4+ após o diagnóstico de HIV+"; "última contagem de CD4+ antes do diagnóstico de câncer"; e "última carga viral antes do diagnóstico de câncer". Somente 12 informavam sobre "primeira contagem de carga viral após diagnóstico de HIV+”. A justificativa para ausência dessas variáveis nos demais prontuários deve-se ao fato de tratar-se de pacientes acompanhados por outras unidades de serviço de assistência especializada em DST/ AIDS do Estado, sendo o histórico desses pacientes no HSJ apenas por serviços de internação e que tiveram como desfecho óbito ou transferência para outra unidade de atendimento antes do resgate do histórico de CD4+ el ou carga viral.

Considerando as informaçôes citadas em relação aos prontuários analisados sobre a primeira contagem de células CD4+ após o diagnóstico de HIV+ (Figura 2), foi encontrada uma variação de 54 células/dL (câncer de pele) a 660 células/dL (câncer de estômago) com média igual a 317,85 células/dL. Para a primeira quantificação da carga viral após o diagnóstico de HIV+ (Figura 2), o valor mínimo foi indetectável (carcinoma) e o valor máximo igual a 4.300.000 cópias/mL (câncer de pênis), sendo a média igual a 462.474 cópias $/ \mathrm{mL}$. Nos casos de linfoma de Hodgkin, esses dados só foram obtidos em 50\% (1) dos prontuários, com contagem de células CD4+ igual

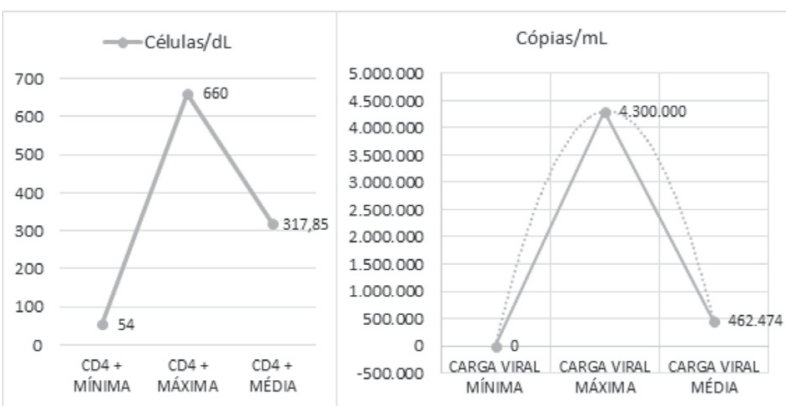

Figura 2. Primeira contagem de células $C D 4+$ e carga viral após diagnóstico de HIV+ em pacientes internados em um hospital de referência de Fortaleza, Ceará, janeiro de 2013 a setembro de 2018

a 596 células/dL e carga viral igual a 5.000 cópias $/ \mathrm{mL}$.

As últimas contagens de células CD4+ obtidas antes do diagnóstico de câncer (Figura 3) variaram de dez (câncer de orofaringe) a 765 células/dL (câncer de estômago) com média igual a 342,23 células/dL. Entre os casos de linfoma de Hodgkin, a contagem máxima antes do diagnóstico de câncer foi de 549 células/dL e a mínima igual a 398 células/dL com média de 473,5 células/dL. Quanto à contagem de carga viral antes do diagnóstico de câncer (Figura 3), a variação foi desde carga viral indetectável (linfoma de Hodgkin; câncer de reto e câncer de cólon) a 9.027.157 cópias $/ \mathrm{mL}$ (linfoma de Hodgkin), com média igual a 1.016.270 cópias/mL.

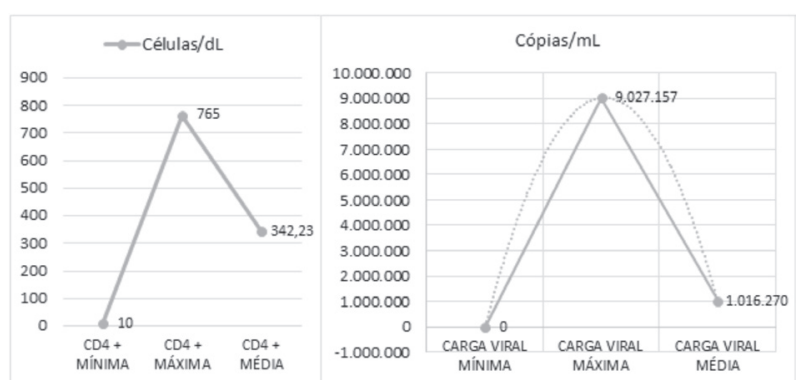

Figura 3. Última contagem de células CD4+ e carga viral de pacientes HIV + internados em um hospital de referência de Fortaleza, Ceará antes do diagnóstico de câncer, janeiro de 2013 a setembro de 2018 
Dos 21 pacientes diagnosticados com câncer não definidores de SIDA, apenas 33,33\% (7) informavam algum tipo de coinfecção. Os principais agentes envolvidos foram os vírus varicela-zoster 28,57\% (2); citomegalovírus 14,28\% (1); fungo Cândida sp 14,28\% (1); bactérias mycobacterium tuberculosis 14,28\% (1); acinetobacter 14,28\% (1); e parasita leishmania sp 14,28\% (1). Nenhum caso de coinfecção foi descrito nos prontuários dos pacientes com linfoma de Hodgkin.

Quanto aos antirretrovirais em uso por cada paciente (Figura 4), 33,3\% (7) possuíam, em seu esquema terapêutico, dois inibidores nucleosídeos de transcriptase reversa associados a dois inibidores de protease; 9,52\% (2) utilizavam dois inibidores nucleosídeos de transcriptase reversa associados a um inibidor de protease; 42,86\% (9), dois inibidores nucleosídeos de transcriptase reversa associados a um inibidor não nucleosídeo de transcriptase reversa; 4,76\% (1), dois inibidores nucleosídeos de transcriptase reversa associados a um inibidor de integrase; e 4,76\% (1), apenas dois inibidores de protease. Somente em 4,76\% (1) dos prontuários (carcinoma anaplásico), não havia informações sobre o esquema terapêutico pelo fato de o paciente náo saber informar quais antirretrovirais utilizava. Para os casos de linfoma de Hodgkin, um (50\%) utilizava como esquema terapêutico dois inibidores nucleosídeos de transcriptase reversa associados a dois inibidores de protease e um (50\%) usava o esquema com dois inibidores nucleosídeos de transcriptase reversa associados a um inibidor não nucleosídeo de transcriptase reversa.

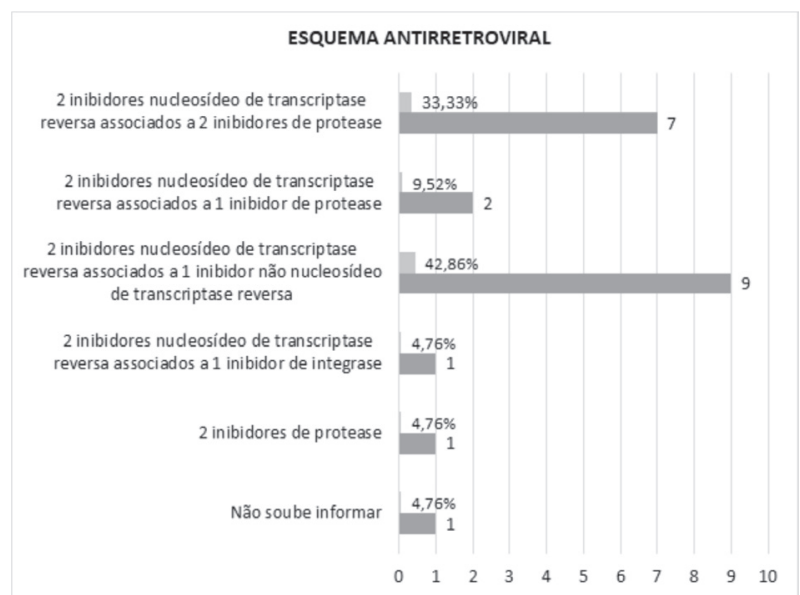

Figura 4. Esquema antirretroviral utilizado pelos pacientes HIV+ diagnosticados com câncer não definidor de SIDA, internados em um hospital de referência de Fortaleza, Ceará, janeiro de 2013 a setembro de 2018

Os inibidores nucleosídeos de transcriptase reversa mais comumente prescritos foram tenofovir (TDF) associado a lamivudina (3TC), presente em 40\% (8) dos 20 esquemas terapêuticos informados. Quanto aos inibidores de protease, o mais comum foi a associação entre lopinavir (LPV) e ritonavir (RTV), presente no esquema de 25\% (5) dos pacientes. Entre os inibidores náo nucleosídeos de transcriptase reversa, o efavirenz (EFZ) foi o único prescrito, constituindo o esquema de $45 \%$ (9) dos pacientes. O dolutegravir foi o único inibidor de integrase prescrito, compondo o esquema de 5\% (1) dos pacientes.

Quando investigado sobre a adesão dos pacientes aos antirretrovirais com base no preenchimento da evolução nos prontuários, pelos médicos, os seguintes dados foram encontrados: $61,9 \%$ (13) dos pacientes apresentaram incumprimento no tratamento, sendo o esquecimento citado como principal motivo; 9,52\% (2) iniciaram terapia antirretroviral somente após internação hospitalar, momento no qual o paciente, além do diagnóstico de câncer, também tomou conhecimento sobre sorologia anti-HIV positivo; 4,76\% (1) tinham abandonado completamente o tratamento; 23,81\% (5) dos prontuários não informavam sobre a assiduidade dos pacientes ao tratamento anti-HIV.

Os principais dados obtidos nos dois pacientes HIV+ antes do diagnóstico de linfoma de Hodgkin, encontrados neste estudo, estão expostos de forma integralizada na Tabela 1, na qual é possível observar em um dos casos CD4+ igual a 549 células/dL, carga viral indetectável e, embora não haja informações sobre o histórico de adesão ao tratamento, possivelmente, trata-se de um paciente com boa adesão à terapia antirretroviral proposta. No segundo caso, o paciente apresenta CD4+ igual a 398 células/dL, carga viral elevada e incumprimento no uso dos antirretrovirais.

\section{DISCUSSÃO}

Neste estudo, entre os cânceres não definidores de SIDA encontrados em pacientes HIV+, o linfoma de Hodgkin ocupou a segunda posição, com a mesma quantidade de casos de câncer de mama e câncer de estômago, ficando abaixo apenas do câncer de pele. Vaccher et al. ${ }^{14}$, em seus estudos epidemiológicos sobre o câncer em pacientes $\mathrm{HIV+}$, a partir de estudos de vinculação de registros nos Estados Unidos da América, Itália e Suíça, que obtiveram 1.078 casos de cânceres não definidores de SIDA, relataram uma possibilidade de risco relativo elevado 50 vezes mais para cânceres relacionados a infecçôes por agentes oncogênicos, denotando atenção especial para o câncer anal, linfoma de Hodgkin, carcinoma hepatocelular e câncer de pulmão. Esses autores informaram haver poucas evidências de risco aumentado para os cânceres epiteliais como o câncer de mama, cólon e próstata. 
Tabela 1. Dados obtidos nos pacientes HIV+ após diagnóstico de linfoma de Hodgkin e internados em um hospital de referência em Fortaleza, Ceará

\begin{tabular}{l|c|c}
\multicolumn{1}{c|}{ INDICADORES } & CASO 1 & CASO 2 \\
\hline Sexo & Masculino & Masculino \\
\hline Idade & 40 anos & 49 anos \\
\hline Tipo de linfoma de Hodgkin & Clássico & Clássico \\
\hline Carga viral antes do diagnóstico de câncer & Indetectável & 9.027 .157 cópias/ML \\
\hline Contagem de CD4 + antes do diagnóstico de câncer & 549 células/DL & 398 células/DL \\
\hline Antirretrovirais utilizados & TDF + 3TC + ATV/RTV & D4T + DDI + EFV \\
\hline Histórico do tratamento & Não informado & Incumprimento \\
\hline
\end{tabular}

Legendas: TDF (tenofovir); 3TC (lamivudina); ATV (atazanavir); RTV (ritonavir); D4T (estavudina); DDI (didanosina); EFZ (efavirenz).

As características relacionadas ao sexo e à idade dos pacientes e ao tipo de linfoma de Hodgkin encontrados neste estudo demostraram perfil semelhante aos dados de uma revisão realizada por Uldrick e Little ${ }^{15}$, que, objetivando descrever a epidemiologia do linfoma de Hodgkin em pacientes HIV+, obteve como resultado para a idade mediana um valor de 40 a 44 anos, evidenciando também, nessa mesma faixa etária, uma correlação entre o linfoma de Hodgkin tipo clássico e o HIV em $14 \%$ dos casos ocorridos nos Estados Unidos.

Segundo Cobucci et al. ${ }^{16}$, um dos fatores contribuintes para o aumento da incidência do linfoma de Hodgkin após a TAAE, deve-se ao fato de as células de Reed Sternberg presentes nesse tipo de neoplasia maligna dependerem das células $\mathrm{CD} 4+$ para se manterem ativas, concluindo assim que este seria um tipo de câncer com chances de surgimento diminuídas quando em indivíduos com situação de imunossupressão grave e aumentando em casos de imunossupressão moderada.

Sendo assim, quando investigado no presente estudo sobre a condição imunológica dos pacientes antes do diagnóstico de linfoma de Hodgkin, considerando a contagem de CD4+ inferior a 200 células como definidor de SIDA, conforme determinado pelo Ministério da Saúde, nos dois casos, nenhum apresentava imunodeficiência. Alguns autores atribuem o parâmetro de normalidade para contagem de células CD4+ em pessoas com HIV e câncer associados ao uso dos antirretrovirais de alta efetividade ${ }^{17}$.

Ao considerar o principal objetivo dos antirretrovirais, que é promover a diminuição da replicaçáo do HIV, o monitoramento da carga viral, um exame que permite quantificar o RNA do vírus circulante no sangue, torna-se um marcador clínico importante, capaz de refletir sobre a dinâmica do retrovírus após o início do tratamento ${ }^{18}$.

Neste estudo, um contraste entre os dois casos de linfoma de Hodgkin foi obtido. Um dos pacientes apresentou carga viral indetectável durante o diagnóstico de câncer, enquanto o segundo mostrou carga viral muito elevada (9.027.157 cópias $/ \mathrm{mL})$, sendo essa contagem a maior encontrada entre todos os cânceres náo definidores de SIDA identificados durante a realização da pesquisa, e possivelmente justificada pelo histórico de incumprimento no uso dos antirretrovirais por parte do paciente.

Embora neste estudo nenhum dos pacientes com linfoma de Hodgkin tenham apresentado imunossupressão e apenas um paciente tenha apontado carga viral elevada, é importante ressaltar que históricos de coinfecçóes com microrganismos, como o EBV, herpes vírus humano tipo 8 , vírus das hepatites $\mathrm{B}$ e $\mathrm{C}$ e o papilomavírus humano (HPV), podem favorecer o surgimento de cânceres ${ }^{19}$.

Carroll e Garzino-Demo ${ }^{12}$ verificaram que a capacidade de hiperprodução de células B induzida pelo HIV pode ser potencializada quando em casos de coinfecçáo pelo EBV, aumentando o risco de recombinaçóes errôneas de genes. As açôes conjuntas desses vírus resultam também nas alteraçôes de hipermutaçôes somáticas e de classes de imunoglobulinas, favorecendo o surgimento e a sobrevida do linfoma.

Em adição, não foram relatadas coinfecçôes em nenhum dos prontuários dos pacientes investigados com linfoma de Hodgkin. Taylor et al. ${ }^{13}$ informam que a coinfecçâo pelo EBV seria a principal diferença do linfoma de Hodgkin entre pessoas com sorologia anti-HIV negativo e pessoas $\mathrm{HIV}_{+}$, sugerindo diferenças importantes também nos mecanismos fisiopatológicos subjacentes.

A multifatoriedade envolvida no processo de manifestaçôes do linfoma de Hodgkin em pessoas HIV+ culmina, na maioria das vezes, para um diagnóstico em estádios mais avançados e agressivos da doença; e, com isso, aumentando ainda mais a complexidade do manejo clínico oncológico nesses pacientes. Portanto, avaliar todos os parâmetros (carga viral, contagem de células $\mathrm{CD} 4+$ ), comumente acompanhados em pacientes que vivem com HIV, incluindo os antirretrovirais em uso, torna-se imprescindível para uma melhor conduta multiprofissional de saúde no tratamento do câncer ${ }^{20}$. 
Um relato de caso envolvendo um paciente HIV+ diagnosticado com linfoma de Hodgkin estádio IV B tratado com ABVD (adriblastina, bleomicina, vimblastina e dacarbazina), sem interrupçáo dos antirretrovirais (TDF associado a 3TC + atazanavir potencializado por RTV), resultou em um histórico de reaçóes adversas à terapia antineoplásica, sendo as principais: febre neutropênica grau 4 e neuropatia grau 2. Os profissionais envolvidos no caso concluíram que as complicaçóes ocorridas no tratamento inicial se deram por interaçôes farmacocinética dos inibidores de protease sobre a vimblastina, e que a troca do antirretroviral por outra classe com efeitos mínimos sobre a enzima CYP4A3 tornaria a quimioterapia mais segura ${ }^{15}$.

Sendo assim, o emprego das classes de antirretrovirais, como os inibidores nucleosídeos e não nucleosídeos de transcriptase reversa e inibidores de integrase associados à primeira linha de tratamento (protocolo $\mathrm{ABVD}$ ) para o linfoma de Hodgkin, por fornecer menor risco de interaçôes farmacocinéticas, torna-se mais seguro ${ }^{15}$.

No presente estudo, um dos pacientes diagnosticados com linfoma de Hodgkin possuía em seu esquema antirretroviral os inibidores de protease atazanavir potencializado com RTV. A fim de evitar reaçóes adversas capazes de comprometer o manejo clínico de paciente HIV+ em uso de antirretrovirais durante o tratamento do câncer, cuidados multiprofissionais, incluindo a farmácia clínica por meio da anamnese farmacêutica, ou seja, recolha do histórico farmacoterapêutico, e a relaçáo interprofissional dos envolvidos na assistência oncológica ao paciente são essenciais.

O estudo realizado apresentou algumas limitaçóes quanto ao acesso aos prontuários ambulatoriais dos pacientes HIV+. Assim sendo, foi dado seguimento à pesquisa a partir dos prontuários de internaçáo dos pacientes que durante a permanência hospitalar foram diagnosticados com câncer não definidor de SIDA. A ausência de dados comumente preenchidos em atendimento ambulatorial a esses pacientes, como contagem de células CD4+ e carga viral, além da necessidade de transferência dos pacientes para centros especializados em oncologia dificultaram na obtenção de alguns dados objetivados nesta pesquisa. Contudo, para os casos de linfoma de Hodgkin encontrados neste estudo, apenas uma informaçáo (primeira contagem de células CD4+ e carga viral após diagnóstico de HIV+) não pôde ser obtida.

\section{CONCLUSÃO}

Vários fatores continuam sendo avaliados na busca por justificativas para os riscos aumentados do surgimento do câncer em pessoas vivendo com HIV em uso de antirretrovirais de alta efetividade.

Os dados obtidos no presente estudo colocam o linfoma de Hodgkin em segundo lugar entre os cânceres não definidores de SIDA encontrados. As variáveis, sexo, idade e até mesmo o subtipo do linfoma de Hodgkin apresentados se assemelham a dados encontrados em estudos realizados fora do Brasil, principal fonte obtida na literatura atualmente.

Em relação à condição imunológica nos pacientes com linfoma de Hodgkin, embora tenha sido obtida a primeira contagem de CD4+ após diagnóstico de HIV + em apenas um dos dois pacientes apresentados no presente estudo, a última contagem antes do diagnóstico de câncer permitiu entender que, ao contrário dos pacientes diagnosticados com câncer de pele, reto, pênis e orofaringe, nenhum dos dois casos de linfoma de Hodgkin passou por estado de imunossupressão grave ou moderada, o que contradiz um dos fatores necessários para o favorecimento de células malignas do linfoma de Hodgkin.

$\mathrm{O}$ mesmo raciocínio aplica-se quanto às variáveis carga viral e uso dos antirretrovirais, pois a não adesão ao tratamento antirretroviral, conforme identificado em um dos casos de linfoma de Hodgkin, pode desencadear resistência viral e aumento da replicação do HIV e favorecer os riscos de coinfecçôes, além da necessidade de substituição dos antirretrovirais, com possível influência negativa sobre o aumento da expectativa de vida desses pacientes, e também dificultar o manejo clínico da infecção e o câncer de forma concomitante por conta do risco do aumento de toxicidade dos antineoplásicos usados na primeira linha para o tratamento do linfoma de Hodgkin. Vale ressaltar ainda que se faz necessário também aumentar o conhecimento sobre as linhas de cuidado multiprofissional, incluindo acompanhamento farmacêutico a esses pacientes, em virtude da alta probabilidade de polimedicação após introdução da quimioterapia antineoplásica e possíveis medicamentos de suporte.

Por fim, as limitaçóes expostas no presente trabalho não permitem concluir sobre a real quantidade de casos de linfoma de Hodgkin entre os demais cânceres não definidores de SIDA ocorridos em pacientes HIV+ na localidade, tampouco estimar a participação do HIV, carga viral, condição imunológica e coinfecções como fatores de risco, conforme dados já evidenciados na literatura estrangeira. Porém, permitem incentivar a execução de novas pesquisas capazes de abranger também dados ambulatoriais e até mesmo de centros especializados em oncologia e onco-hematologia, para que, entâo, seja possível uma melhor descrição do perfil não só dos casos de linfomas de Hodgkin, mas também de outras neoplasias não definidoras de SIDA em pacientes HIV+. 


\section{CONTRIBUIÇÕES}

Todos os autores contribuíram na concepção e/ ou no planejamento do estudo; na obtenção, análise e interpretação dos dados; assim como na redação e revisão crítica; e aprovaram a versão final a ser publicada.

\section{AGRADECIMENTOS}

À equipe do SAME do HSJ.

\section{DECLARAÇÃO DE CONFLITO DE INTERESSES}

Nada a declarar.

\section{FONTES DE FINANCIAMENTO}

Não há.

\section{REFERÊNCIAS}

1. Stanfield CL. Fisiologia Humana. 5ed. São Paulo: Person; 2014. Capítulo 23, Sistema imune; p. 811

2. Clifford GM, Polesel J, Rickenbach M, et al. Cancer risk in the swiss hiv cohort study: associations with immunodeficiency, smoking, and highly active antiretroviral therapy. J Natl Cancer Inst. 2005;97(6):42532. doi: https://doi.org/10.1093/jnci/dji072

3. Ministério da Saúde (BR), Secretaria de Vigilância em Saúde. Boletim epidemiológico HIV AIDS: 2017. Brasília, DF: Ministério da Saúde; 2017.

4. Instituto Nacional de Câncer José Alencar Gomes da Silva. Estimativa 2018: incidência de câncer no Brasil [Internet]. Rio de Janeiro: INCA; 2017 [acesso 2018 jul 10]. Disponível em: http://www.epi.uff.br/wp-content/ uploads/2013/08/estimativa-incidencia-de-cancer-nobrasil-2018.pdf

5. Atlas on-line de mortalidade [Internet]. Rio de Janeiro: INCA; c1996-2014 [acesso 2018 jul 10]. Disponível em: https://mortalidade.inca.gov.br/MortalidadeWeb/pages/ Modelo01/consultar.xhtml;jsessionid=16D87A70D7BB 5F0772AB31D83C7DA767\#panelResultado

6. Howlader N, Noone AM, Krapcho M, et al. SEER cancer statistics review, 1975-2014 [Internet]. Bethesda: National Cancer Institute; 2017 [cited 2018 Aug 1]. Available from: https://seer.cancer.gov/csr/1975_2014/

7. Arnold M, Sierra MS, Laversanne M, et al. Global patterns and trends in colorectal cancer incidence and mortality. Gut. 2017;66(4):683-91. doi: http://doi. org/10.1136/gutjnl-2015-310912

8. Canadian Cancer Society. Canadian cancer statistics 2015 special topic: predictions of the future burden of cancer in Canada. Toronto, CA: Canadian Cancer Society; 2015 May.
9. American Cancer Society [Internet]. Atlanta: American Cancer Society; c2021. Non-Hodgkin Lymphoma Risk Factors [revised 2020 June 9; cited 2018 Aug 1]. Available from: https://www.cancer.org/content/cancer/en/cancer/ non-hodgkin-lymphoma/causes-risks-prevention/riskfactors/

10. Centers for Disease Control and Prevention (US) [Internet]. Atlanta (GA): Centers for Disease Control and Prevention (US); [date unknown]. Lymphoma [revised 2018 May 29; cited 2018 July 10]. Available from: https://www.cdc.gov/cancer/lymphoma/

11. Instituto Nacional de Câncer José Alencar Gomes da Silva. Estimativa 2020: incidência de câncer no Brasil. Rio de Janeiro: INCA; 2019.

12. Carroll V, Garzino-Demo A. Hiv-associated lymphoma in the era of combination antiretroviral therapy: shifting the immunological landscape. Pathog Dis. 2015;73(7):ftv044. doi: https://doi.org/10.1093/ femspd/ftv044

13. Taylor JG, Liapis K, Gribben JG. The role of the tumor microenvironment in HIV- associated lymphomas. Biomark Med. 2015;9(5):473-82. doi: https://doi. org/10.2217/bmm.15.13

14. Vaccher E, Serraino D, Carbone A, et al. The evolving scenario of non-aids-defining cancers: challenges and opportunities of care. Oncologist. 2014;19(8):860-7. doi: https://doi.org/10.1634/theoncologist.2014-0024

15. Uldrick TS, Little RF. How I treat classical Hodgkin lymphoma in patients infected with human immunodeficiency virus. Blood. 2015;125(8):1226-35. doi: https://doi.org/10.1182/blood-2014-08-551598

16. Cobucci RNO, Lima PH, Souza PC, et al. Assessing the impact of HAART on the incidence of defining and nondefining AIDS cancers among patients with HIV/AIDS: a systematic review. J Infect Public Health. 2014;8(1):110. doi: https://doi.org/10.1016/j.jiph.2014.08.003

17. Totonchy J, Cesarman E. Does persistent hiv replication explain continued lymphoma incidence in the era of effective antiretroviral therapy? Curr Opin Virol. 2016;20:71-7. doi: https://doi.org/10.1016/j. coviro.2016.09.001

18. LeMessurier J, Traversy G, Varsaneux O, et al. Risk of sexual transmission of human immunodeficiency vírus with antiretroviral therapy, suppressed viral load and condom use: a systematic review. CMAJ. 2018;190(46):E1350-E60. doi: https://doi.org/10.1503/ cmaj. 180311

19. Freitas JB, Gagliani LH, Caseiro MM, et al. Perfil epidemiológico dos pacientes infectados pelo HIV com e sem câncer em um hospital público na Baixada Santista - SP - Brasil. Rev. UNILUS Ensino Pesqui. 2017;14(34):17-24.

20. Bachanova V, Connors JM. Hodgkin lymphoma in the elderly, pregnant, and hiv-infected. Semin Hematol. 
2016;53(3):203-8. doi: https://doi.org/10.1053/j. seminhematol.2016.05.002

Recebido em 31/7/2020

Aprovado em 23/11/2020 